\title{
Northern Hemisphere spring snow cover variability and change over 1922-2010 including an assessment of uncertainty
}

\author{
R. D. Brown ${ }^{1}$ and D. A. Robinson ${ }^{2}$ \\ ${ }^{1}$ Climate Processes Section, Climate Research Division, Environment Canada @ Ouranos, 550 Sherbrooke St. West, \\ 19th Floor, Montréal, QC, H3A 1B9, Canada \\ ${ }^{2}$ Department of Geography, Rutgers University, 54 Joyce Kilmer Avenue, Piscataway, NJ 08854-8054, USA
}

Received: 5 November 2010 - Published in The Cryosphere Discuss.: 24 November 2010

Revised: 22 February 2011 - Accepted: 27 February 2011 - Published: 16 March 2011

\begin{abstract}
An update is provided of Northern Hemisphere (NH) spring (March, April) snow cover extent (SCE) over the 1922-2010 period incorporating the new climate data record (CDR) version of the NOAA weekly SCE dataset, with annual 95\% confidence intervals estimated from regression analysis and intercomparison of multiple datasets. The uncertainty analysis indicates a $95 \%$ confidence interval in NH spring SCE of $\pm 5-10 \%$ over the pre-satellite period and $\pm 3-5 \%$ over the satellite era. The multi-dataset analysis shows larger uncertainties monitoring spring SCE over Eurasia (EUR) than North America (NA) due to the more complex regional character of the snow cover variability and larger between-dataset variability over northern Europe and north-central Russia.

Trend analysis of the updated SCE series provides evidence that $\mathrm{NH}$ spring snow cover extent has undergone significant reductions over the past $\sim 90 \mathrm{yr}$ and that the rate of decrease has accelerated over the past $40 \mathrm{yr}$. The rate of decrease in March and April NH SCE over the 1970-2010 period is $\sim 0.8$ million $\mathrm{km}^{2}$ per decade corresponding to a $7 \%$ and $11 \%$ decrease in NH March and April SCE respectively from pre-1970 values. In March, most of the change is being driven by Eurasia (NA trends are not significant) but both continents exhibit significant SCE reductions in April.

The observed trends in SCE are being mainly driven by warmer air temperatures, with $\mathrm{NH}$ mid-latitude air temperatures explaining $\sim 50 \%$ of the variance in $\mathrm{NH}$ spring snow cover over the 89 -yr period analyzed. However, there is also evidence that changes in atmospheric circulation around 1980 involving the North Atlantic Oscillation and Scandinavian pattern have contributed to reductions in March SCE over Eurasia.
\end{abstract}

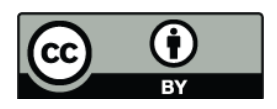

Correspondence to: R. Brown (brown.ross@ouranos.ca)

\section{Introduction}

Reliable information on spatial and temporal variability in continental and hemispheric snow cover extent (SCE) is important for climate monitoring (e.g. Arndt et al., 2010), climate model evaluation (e.g. Foster et al., 1996; Frei et al., 2005; Roesch, 2006; Brown and Frei, 2007) and cryosphereclimate feedback studies (e.g. Hall and Qu, 2006; Fernandes et al., 2009; Flanner et al., 2011). Previously published estimates of Northern Hemisphere (NH) monthly SCE used for evaluating climate models and monitoring variability and change in hemispheric SCE have typically been based on single datasets such as the National Oceanic and Atmospheric Administration (NOAA) weekly snow cover dataset (Robinson et al., 1993) or passive microwave-derived snow cover data (Armstrong and Brodzik, 2001), with little or no information on the likely range of uncertainty in the observations. Brown et al. (2010) showed there can be large differences in the amount of snow cover seen by different satellite sensors related to spatial resolution, cloud cover (for optical sensors) and wavelength specific interactions with the atmosphere, snowpack, terrain and land cover. Estimates of SCE derived from surface-based observations also have spatially and temporally varying uncertainties related to the uneven distribution of in situ observations.

Brown (2000) presented estimates of historical variability in NH March and April snow cover extent (SCE) over the 1922-1997 period that were subsequently updated and included in the 4th IPCC Assessment (Lemke et al., 2007; Figs. SPM.3, TS.12 and 4.2). The hemispheric reconstruction was restricted to only these two months due to limitations in the spatial coverage of historical snow depth observations. The 2007 update included an estimate of uncertainty derived from the interannual variability of the SCE series, as no published estimates were available of the uncertainty in the in situ-based SCE reconstruction developed by Brown (2000) or in the NOAA satellite dataset used to

Published by Copernicus Publications on behalf of the European Geosciences Union. 
monitor NH SCE since 1966 (Robinson et al., 1993). The fixed uncertainty interval applied in the IPCC report does not reflect the different uncertainty levels associated with the presatellite in situ-based SCE information, or improvements in snow mapping over the satellite era from increases in satellite resolution and frequency.

Brown et al. (2010) used a multi-dataset approach to estimate the observational uncertainty in Arctic spring SCE over the 1967-2008 period. This approach is applied here to provide estimates of the uncertainty in the NH spring SCE series presented in the 4th IPCC Assessment and to update the series using the new climate data record (CDR) version of the NOAA dataset (http://climate.rutgers.edu/snowcover). This version includes corrections to account for a change in mapping procedures that took place in 1999 (Ramsay, 1998; Helfrich et al., 2007). The updated series (with estimated uncertainty levels) is used to document trends in NH spring SCE over the period from the early 1920s, and to examine associations with air temperature and atmospheric circulation.

\section{Datasets}

The various sources of snow cover data used in this study are summarized in Table 1. Detailed descriptions of these datasets are provided by Brown et al. (2010) and are not repeated here. The NH March and April SCE series presented in the 4th IPCC assessment were based on the historical snow cover index of Brown (2000) (henceforth defined as B2000) up to the start of the satellite era in the late-1960s, with SCE values after 1966 obtained from the NOAA weekly dataset (Robinson et al., 1993). The B2000 index was derived from reconstructed and observed daily snow depth over a fixed network of climate stations and is available over North America (NA) from 1915-1992 for the months of November to April, but is limited to October, March and April over Eurasia (EUR) for the 1922-1991 period due to a sparser network of observations. Consequently this dataset only provides hemispheric information in the months of March and April from 1922-1991. McCabe and Wolock (2010) reconstructed NH March SCE back to 1902 using gridded monthly temperature and precipitation data from the Climatic Research Unit (CRU) in a simplified snow accumulation and melt model calibrated with the NOAA SCE dataset to define temperature thresholds for rain-snow probability and melt rate. The results agree reasonably closely with the B2000 series (not surprisingly since SCE and air temperature are strongly correlated over the NH in March) but the method is not considered to be particularly robust because of the monthly timestep, the use of non-physically based temperature thresholds, and the fact the method requires calibration with the NOAA SCE series.

The NOAA dataset is based on weekly charts of snow cover extent derived from manual interpretation of visible satellite imagery up to 1999 . The charting method changed in May 1999 with the introduction of the higher resolution $24 \mathrm{~km}$ daily Interactive Multi-Sensor (IMS) snow cover product (Ramsay, 1998). A pseudo-weekly product is automatically derived from the IMS $24 \mathrm{~km}$ daily product assuming the analysis for Monday is representative of the previous week. This change was found to map less snow in mountain regions and has been corrected in the CDR version of the NOAA dataset. SCE was derived with the monthly version of the CDR dataset which gives the fraction of the month that snow cover was present. While efforts have been made to correct for changes in charting procedures in the CDR dataset, it is not possible to correct for any technological bias related to the increase in the volume and resolution of satellite information over time as well as variations in analyst experience and improvements in analysis tools. However, these errors are expected to be small compared to seasonal and interannual fluctuations in continental snow cover extent, and comparison of NOAA SCE over NA and EUR with a multi-dataset average (Sect. 4.1) showed that the difference series did not contain any trend which provides some evidence that these errors are not affecting the homogeneity of continental SCE in March and April.

The other datasets shown in Table 1 (B2003, CMC, ERA40, ERA40-rec, NCEP, and PMW) were used to establish the confidence interval in March and April hemispheric SCE series as outlined in Sect. 3. The CMC and B2003 SCE series were combined (henceforth referred to as B2003+CMC) to provide additional NA monthly SCE series for estimating confidence intervals. These two datasets used different precipitation and temperature products to derive the first-guess snow depth field for optimal interpolation of surface snow depth observations, but SCE should be largely insensitive to the background field in the November-April period when the snow line fluctuates across the mid-latitudinal zone of NA where there is a dense network of surface observations (Brown, 2000).

\section{Methodology}

The development of estimates of uncertainty in $\mathrm{NH}$ spring SCE series over the 1922-2010 period required the use of two different strategies based on the temporal distribution of the available datasets. For the earlier period of record where the only estimate was the B2000 snow cover index, the $95 \%$ confidence intervals were estimated from regression against the multi-dataset average anomaly over the 19671992 period of overlapping data using the regression forecast error method described in Sect. 3.1 below. The multi-dataset method outlined in Sect. 3.2 was used to estimate the confidence interval when there were at least 5 datasets available which coincided with the period 1967-2002. Confidence intervals in the period from 2003-2010 were estimated from the regression of NOAA against the CMC operational analysis over the 1998-2010 period of overlapping data; the CMC 
Table 1. Summary of data sources used in the analysis.

\begin{tabular}{|c|c|c|c|c|}
\hline Acronym & Dataset Description & Period & Resolution & Data Source \\
\hline B2000 & $\begin{array}{l}\text { Monthly snow cover index for NA and Eurasia } \\
\text { based on gridded observed and reconstructed } \\
\text { daily snow depth at surface climate stations }\end{array}$ & $\begin{array}{l}\text { NA, 1915-1992 } \\
\text { EUR, 1922-1991 }\end{array}$ & $190.5 \mathrm{~km}$ & Brown (2000) \\
\hline B2003 & $\begin{array}{l}\text { Daily snow depth analysis over NA from } \\
\text { optimal interpolation of historical in situ snow } \\
\text { depth observations }\end{array}$ & 1979-1997 & $\sim 35 \mathrm{~km}$ & Brown et al. (2003) \\
\hline $\mathrm{CMC}$ & $\begin{array}{l}\text { Canadian Meteorological Centre global daily } \\
\text { snow depth analysis from optimal interpolation } \\
\text { of real-time in situ observations }\end{array}$ & 1998-2010 & $\sim 35 \mathrm{~km}$ & $\begin{array}{l}\text { National Snow and Ice } \\
\text { Data Center (NSIDC), } \\
\text { Brasnett (1999) }\end{array}$ \\
\hline ERA-40 & $\begin{array}{l}\text { ERA-40 reanalysis daily snow depths } \\
\text { from assimilated surface observations }\end{array}$ & $1957-2002$ & $\sim 275 \mathrm{~km}$ & $\begin{array}{l}\text { European Centre for } \\
\text { Medium-Range Weather } \\
\text { Forecasts (ECMWF), } \\
\text { Uppala et al. (2005). }\end{array}$ \\
\hline ERA-40rec & $\begin{array}{l}\text { ERA-40 reconstructed snow cover duration } \\
\text { with temperature-index snow model of Brown } \\
\text { et al. }(2003)\end{array}$ & 1957-2002 & $\begin{array}{l}\sim 275 \mathrm{~km} \\
\text { (with } 5 \mathrm{~km} \text { em- } \\
\text { pirical elevation } \\
\text { adjustment) }\end{array}$ & Brown et al. (2010) \\
\hline NCEP & $\begin{array}{l}\text { Snow cover proxy derived from National } \\
\text { Centers for Environmental Prediction } \\
\text { Reanalysis daily temperatures (land area inside } \\
\text { the } 0^{\circ} \mathrm{C} \text { isotherm) }\end{array}$ & 1948-2008 & $\sim 275 \mathrm{~km}$ & $\begin{array}{l}\text { Brown et al. (2010), Earth } \\
\text { System Research } \\
\text { Laboratory, NOAA, } \\
\text { Kalnay et al. (1996) }\end{array}$ \\
\hline NOAA & $\begin{array}{l}\text { National Oceanic and Atmospheric } \\
\text { Administration weekly snow/no-snow charts }\end{array}$ & 1966-2010 & $190.5 \mathrm{~km}$ & $\begin{array}{l}\text { Rutgers, U., } \\
\text { Robinson et al. (1993) }\end{array}$ \\
\hline PMW & $\begin{array}{l}\text { Snow water equivalent from Scanning } \\
\text { Multichannel Microwave Radiometer (SMMR, } \\
\text { 1978-1987) and the Special Sensor } \\
\text { Microwave/Imager (SSM/I, 1987-2008) }\end{array}$ & 1978-2008 & $24 \mathrm{~km}$ & NSIDC, Savoie et al. (2009) \\
\hline
\end{tabular}

SCE estimates represent an independent source of SCE information that is highly correlated to the NOAA dataset in March and April (see bottom row Table 2) when the snow line is located where the observing network is relatively dense. The B2000 and NOAA datasets were retained as the base series for applying the confidence intervals to maintain the continuity of the series presented in Brown (2000) and the 4th IPCC Assessment, and because there is greater confidence in the homogeneity of these series.

\subsection{Regression-based estimate of confidence interval}

Regression analysis was used to estimate the confidence interval from the standard error of forecast $\left(\mathrm{SE}_{\mathrm{f}}\right)$ when there were insufficient datasets to compute a multi-dataset estimate of the confidence interval. SCE series were converted to standardized anomalies with respect to the period of the regression analysis which makes the error analysis insensitive to the choice of dependent and independent variables, and reduces the computation of $\mathrm{SE}_{\mathrm{f}}$ in each year to Eq. (1) as the anomaly series has a standard deviation of 1 , and the mean and sum of the anomaly series are both 0 .

$\mathrm{SE}_{\mathrm{f}}=\mathrm{SE}_{\mathrm{res}} \sqrt{\left[\left(1+(1 / n)\left(1+x_{i}^{2}\right)\right)\right.}$

where $\mathrm{SE}_{\mathrm{res}}$ is the standard error of the residuals from the best fit line, $x_{i}$ is the standardized anomaly of the independent variable in year $i$, and $n$ is the number of pairs of anomalies included in the regression analysis. A $95 \%$ confidence interval is then obtained from $\pm t_{c} \mathrm{SE}_{\mathrm{f}}$ where $t_{c}$ is the Student's $t$-statistic corresponding to 0.05 level of significance for $n-1$ degrees of freedom. An estimate of the root mean squared error in the dependent data was obtained from a standard leave-one-out cross-validation (LOOCV) analysis.

\subsection{Multi-dataset estimate of confidence interval}

Confidence intervals were estimated from the standard error of the multiple datasets over the 1967-2002 period when there were at least five datasets available in any given year. The five dataset minimum was imposed to reduce variability 
Table 2. Correlation and root mean square differences (rmsd) in detrended SCE anomalies versus the multi-dataset average anomaly (excluded the dataset being evaluated) in three periods of data overlap. The units of rmsd are dimensionless (standardized anomalies). The correlations and rmsd (from LOOCV) are also shown for the regression analyses used to estimate the confidence interval in B2000 prior to 1967 and for NOAA after 2002. All correlations are statistically significant at the 0.05 level.

\begin{tabular}{|c|c|c|c|c|c|c|c|c|}
\hline \multirow{3}{*}{$\begin{array}{l}\text { Dataset overlap period: } \\
\text { 1959-1991 }\end{array}$} & \multicolumn{4}{|c|}{ North America } & \multicolumn{4}{|c|}{ Eurasia } \\
\hline & \multicolumn{2}{|c|}{ March } & \multicolumn{2}{|c|}{ April } & \multicolumn{2}{|c|}{ March } & \multicolumn{2}{|c|}{ April } \\
\hline & $\mathrm{r}$ & rmsd & $\mathrm{r}$ & rmsd & $\mathrm{r}$ & rmsd & $\mathrm{r}$ & rmsd \\
\hline B2000 & 0.87 & 0.45 & 0.90 & 0.41 & 0.85 & 0.53 & 0.78 & 0.61 \\
\hline ERA-40 & 0.73 & 0.67 & 0.83 & 0.53 & 0.86 & 0.49 & 0.72 & 0.68 \\
\hline ERA-40rec & 0.81 & 0.56 & 0.92 & 0.37 & 0.95 & 0.30 & 0.91 & 0.42 \\
\hline NCEP & 0.67 & 0.73 & 0.77 & 0.61 & 0.87 & 0.50 & 0.78 & 0.56 \\
\hline \multicolumn{9}{|l|}{$\begin{array}{l}\text { Dataset overlap period: } \\
\text { 1979-2002 }\end{array}$} \\
\hline B2003+CMC & 0.95 & 0.33 & 0.91 & 0.38 & \multicolumn{2}{|c|}{$\mathrm{n} / \mathrm{a}$} & \multicolumn{2}{|c|}{$\mathrm{n} / \mathrm{a}$} \\
\hline ERA-40 & 0.66 & 0.75 & 0.84 & 0.53 & 0.87 & 0.40 & 0.81 & 0.54 \\
\hline ERA-40rec & 0.87 & 0.48 & 0.91 & 0.41 & 0.89 & 0.37 & 0.84 & 0.45 \\
\hline NCEP & 0.72 & 0.68 & 0.91 & 0.39 & 0.80 & 0.51 & 0.91 & 0.44 \\
\hline NOAA & 0.84 & 0.54 & 0.90 & 0.43 & 0.65 & 0.65 & 0.62 & 0.74 \\
\hline PMW & 0.88 & 0.42 & 0.86 & 0.47 & 0.77 & 0.60 & 0.70 & 0.71 \\
\hline $\begin{array}{l}\text { Regression analysis } \\
\text { results for B2000 } \\
\text { versus multi-dataset for } \\
1967-1992 \text { period }\end{array}$ & 0.94 & 0.28 & 0.91 & 0.34 & 0.91 & 0.34 & 0.84 & 0.48 \\
\hline $\begin{array}{l}\text { Regression analysis } \\
\text { results for NOAA } \\
\text { versus CMC for } \\
1998-2010 \text { period }\end{array}$ & 0.97 & 0.22 & 0.99 & 0.16 & 0.98 & 0.18 & 0.91 & 0.43 \\
\hline
\end{tabular}

due to sample size. The datasets available in this period were B2000 (up to 1992), B2003+CMC (NA only from 1979), ERA-40, ERA-40rec, NCEP, NOAA, and PMW. Datasets were converted to standardized anomalies for a 1979-2002 reference period and an estimate of the confidence interval in monthly SCE obtained from the standard error (SE) of the average multi-dataset standardized anomaly series computed from

$\mathrm{SE}=s / \sqrt{(n-1)}$

which depends on the standard deviation, $s$, of the $n$ datasets included in the average anomaly. The $95 \%$ confidence interval was then computed from $\pm t_{c} \mathrm{SE}$ as previously defined. The B2000 series was padded with values estimated from regression against the NOAA dataset for the 1993 to 2002 period to convert the series to anomalies with respect to the 1979-2002 reference period. The error estimates were converted back to SCE in units of $10^{6} \mathrm{~km}^{2}$ using the reference period mean and standard deviation from the NOAA dataset.

An evaluation of the degree of consistency between datasets in March-April was carried out as part of the multidataset uncertainty analysis over two periods of dataset overlap: 1959-1991, and 1979-2002. This included the correlation and root mean square difference between detrended SCE anomalies for each dataset and the multi-dataset average anomaly series (excluding the dataset being evaluated).

\section{Results}

\subsection{Dataset evaluation}

The dataset evaluation results for March and April separated by continent (Table 2 ) show a clear contrast in dataset consistency between the two continents in April with most datasets exhibiting closer agreement over NA than EUR. The NOAA dataset is a case in point; it had the lowest agreement with the multi-dataset average over EUR in March-April in the 19792002 overlap period but had comparable correlations to the other datasets over NA in the same period. The reason for the overall greater dataset consistency over NA is likely related to the more regionally constrained character of the continental snow cover variability compared to EUR which is clearly seen in the principal component analysis of NH SCE variability provided by Frei and Robinson (1999). Other noteworthy points are the generally strong performance of the in situ based estimates of SCE (B2000 and B2003+CMC) and the fact that downscaling SCE from ERA-40 temperature and precipitation provided superior results than SCE derived from ERA-40 snow depth fields. There was no evidence of any systematic trends or step changes in the difference series between NOAA and the multi-dataset average in March and April over the 1967 to 2002 period (not shown), confirming the work by the Rutgers Global Snow Lab to maintain the homogeneity of the NOAA snow cover series.

To gain further insight into the spatial pattern of betweendataset variability, data were interpolated to a common $190.5 \mathrm{~km}$ polar stereographic grid and the standard deviation contoured (Fig. 1, top panels). The analysis was carried out with the monthly snow cover anomaly series to reduce the impact of topographic influences on the interpolation process and remove systematic differences in how each dataset "sees" snow cover. The PMW dataset was excluded from the analysis, as the spatial pattern of snow cover deviated significantly from the other datasets in mountainous areas and around the southern boundary of the snow line. Not surprisingly, the main zone of dataset variability follows the snow line position in each month, as shown by the $50 \%$ mean snow cover contour for the multi-dataset average, with the largest dataset variability located over northern Europe and northcentral Russia in March. The dataset variability is lower in April with the Eurasian zone of maximum dataset variability remaining over the western part of the continent while the variability is more-or-less evenly spread along the mean position of the snow-line in NA. In general, the spatial pattern and relative magnitude of the results follow the interannual variability in snow cover (Fig. 1, bottom panels) with the exception of eastern Eurasia and the Tibetan plateau where the between-dataset variability is lower. These results should not be confused with those shown in Table 2 which are computed with monthly values of continental SCE. 


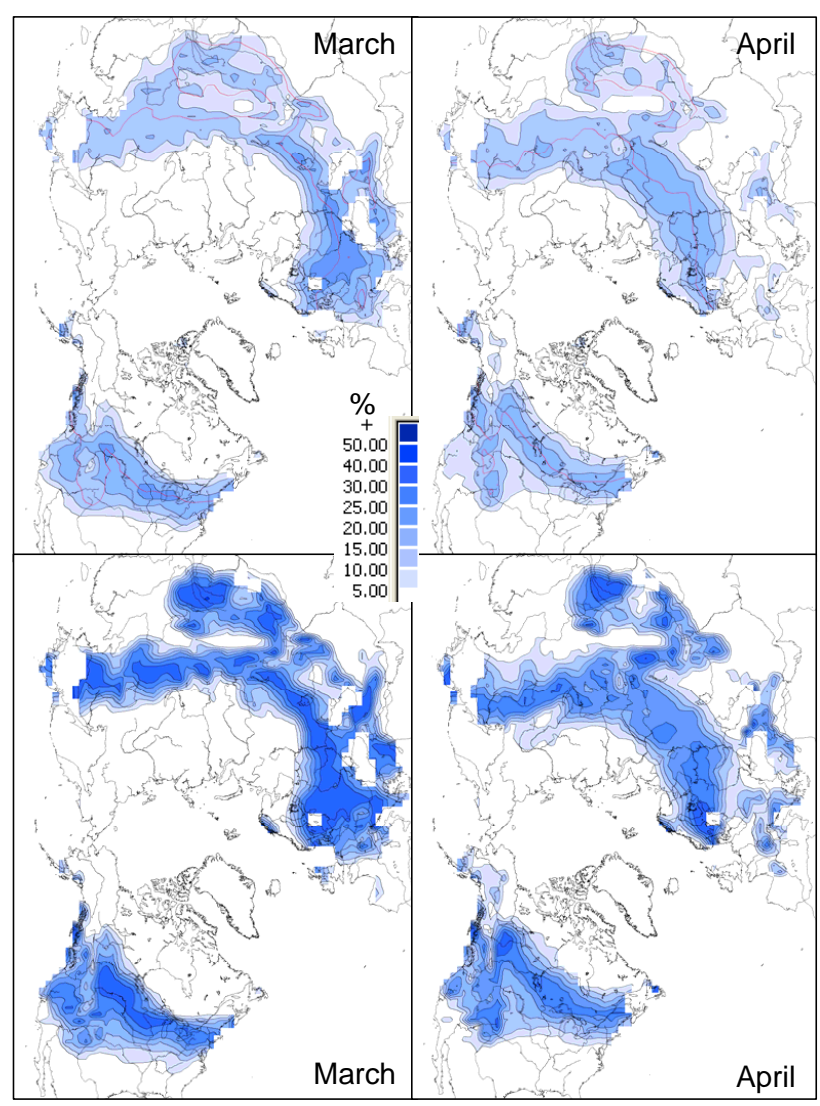

Fig. 1. Top: spatial pattern of between-dataset variability expressed as the average annual standard deviation in monthly snow cover anomalies over the 1979-2002 period for five datasets with data in the 1979-2002 overlap period (excluding PMW). The red line shows the mean position of the multi-dataset $50 \%$ snow cover contour. Bottom: spatial pattern of interannual variability in snow cover over the same period from the standard deviation in monthly snow cover fraction computed with the NOAA dataset. Units are \% snow cover fraction.

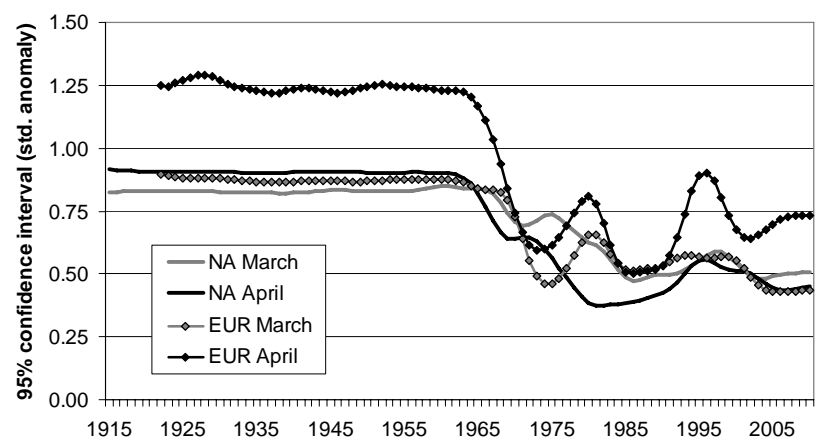

Fig. 2. Smoothed (13-term binomial filter) values of the $95 \%$ confidence interval in standardized SCE anomalies computed from the two methods outlined in Sect. 3.

\subsection{Confidence interval}

The results of the confidence interval analysis for March and April SCE are shown in Fig. 2 for both continents. The values are smoothed with a 13-term binomial filter to facilitate the comparison, as the estimated confidence intervals from the multi-dataset method can vary greatly from one year to the next. The uncertainty is highest in the period prior to 1967 when the estimate is based solely on the regression analysis and decreases rapidly over the 1970s and 1980s in response to an increase in the number of datasets and increased frequency and resolution of snow cover information. The larger confidence interval for Eurasia April SCE is evident reflecting the larger differences between datasets noted previously. The confidence limits are shown in Fig. 3 for NH SCE expressed as percentages of monthly SCE. These range from $\pm 5 \%$ to $\pm 9 \%$ for March and April SCE over the early period of record to $\pm 3 \%$ to $\pm 5 \%$ over the more recent period of satellite-based observations.

\subsection{Analysis of updated SCE series including estimated confidence interval}

The estimated confidence intervals were applied to the merged B2000 and NOAA SCE anomaly series to update the SCE series published in Brown (2000) (Fig. 4). The final NH series were converted to SCE in million $\mathrm{km}^{2}$ using the 19792002 reference period mean and standard deviation from the NOAA dataset (Fig. 5). A 13-term binomial filter was applied to remove fluctuations on less than decadal time scales following the approach used in the 4th IPCC Assessment (Trenberth et al., 2007, Appendix 3.A). The updated anomaly series in Fig. 4 show that NA March SCE increased over the first half of the 20th Century followed by a period of rapid decrease in the late-1980s and early-1990s that rebounded slightly during the late-1990s. Over Eurasia, March SCE has remained more or less stable from the 1920s up to the end of the 1980s when SCE underwent a similar rapid step decrease as NA to lower values that have remained more or less constant since. The NA April SCE series shows some similarity to March with the notable point that the 2010 anomaly is the lowest in the $96 \mathrm{yr}$ period (the second warmest April over NA mid-latitudes after 1987 based on air temperature anomalies averaged over $40-60^{\circ} \mathrm{N}$ for each continent from the CRUTEM3 dataset (Brohan et al., 2006). Eurasian April SCE differs from NA with more evidence of long-term decreases over the entire period of record. The rapid reductions in SCE in the late-1980s and early 1990s seen in both continents in March and April coincide with a change in NH circulation patterns to more positive values of the North Atlantic and Arctic Oscillations (Watanabe and Nitta, 1999; Overland et al., 1999).

Analysis of secular variability in the relationship between winter (January-March) values of the leading 10 modes of $\mathrm{NH}$ atmospheric variability computed by the 


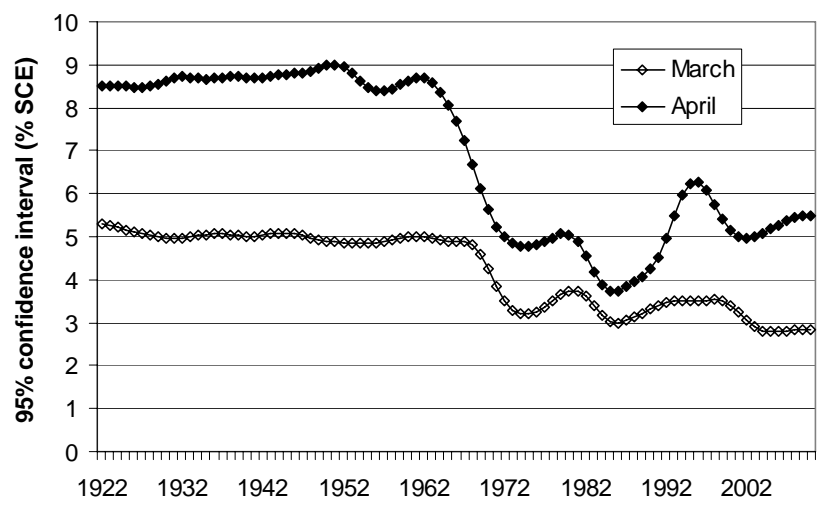

Fig. 3. Smoothed (13-term binomial filter) $95 \%$ confidence intervals for NH March and April SCE expressed as a \% of the corresponding mean SCE.

Climate Prediction Center (http://www.cpc.noaa.gov/data/ teledoc/telecontents.shtml) and NH SCE with 21-yr running correlations over the period from 1951-2010 showed evidence of an abrupt strengthening of the relationship between the North Atlantic Oscillation (NAO) and NH March SCE around 1980, and an increase in the importance of the Scandinavian (SCA) pattern over the period after the mid-1980s (Fig. 6). The SCA pattern (originally referred to as the Eurasia-1 pattern by Barnston and Livezey, 1987) describes the strength of the quasi-permanent ridge of winter high pressure over Scandinavia and northern Europe with positive (negative) values of SCA contributing to cold (warm) March temperature anomalies over central Eurasia and to an opposite response over northwestern NA (Fig. 7, top panel). NAO has been shown to be a significant factor in winter precipitation and snow cover variability across western Europe and eastern North America (Gutzler and Rosen, 1992; Clark et al., 1999; Bednorz, 2004; Henderson and Leathers, 2010) and positive (negative) values of NAO contribute to warm (cold) March temperature anomalies over central Eurasia (Fig. 7, bottom panel) and an opposite albeit weaker response over NA. Prior to the mid-1980s, NAO and SCA were not significantly correlated but since then the two patterns exhibit a significant negative correlation that reinforces the influence on temperature anomalies. The two patterns have also tended to be in modes that favor warm winter temperature anomalies over Eurasia since 1980 (Fig. 8). The same analysis for April (not shown) revealed similar evidence of an increase in the importance of NAO around 1980 but the correlations were much weaker than March and ceased to be statistically significant after about 1990 . There were no sustained significant correlations between April SCE and the SCA index over the 1951-2010 period. While atmospheric circulation may be playing a role in some of the recent SCE decreases, long-term changes in air temperature dominate the hemispheric response of spring SCE with $\mathrm{NH}$ mid-latitude air temperatures explaining $\sim 50 \%$ of the variance in $\mathrm{NH}$ spring snow cover over the 89-yr period analyzed (Fig. 9).
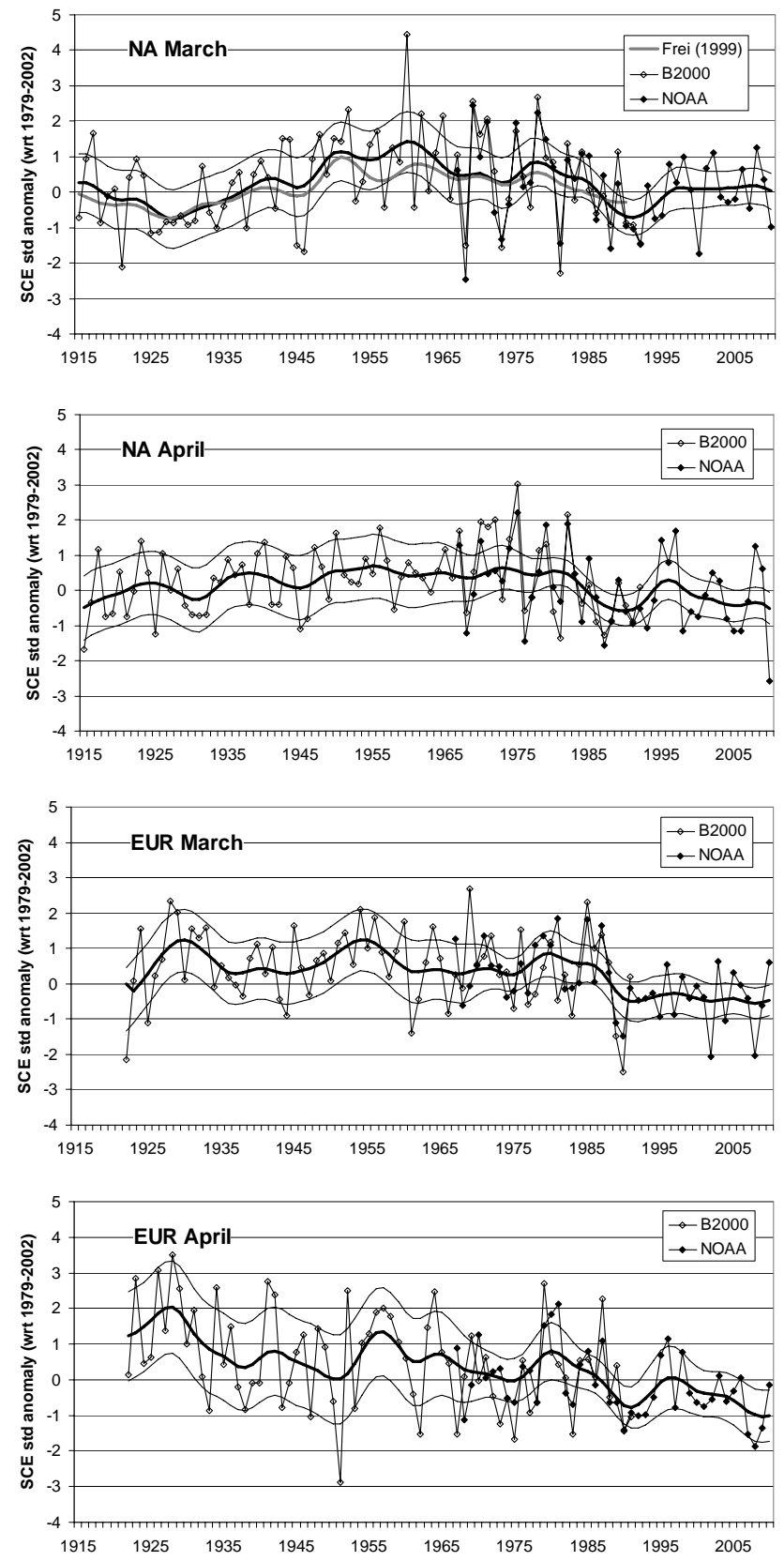

Fig. 4. Variability in NA and EUR March and April SCE anomalies over the periods of available data with 13-term filtered values of the mean and $95 \%$ confidence interval. The grey smoothed line in NA March is filtered values of the Frei et al. (1999) reconstruction. The width of the smoothed confidence interval is also influenced by the interannual variability in SCE. 

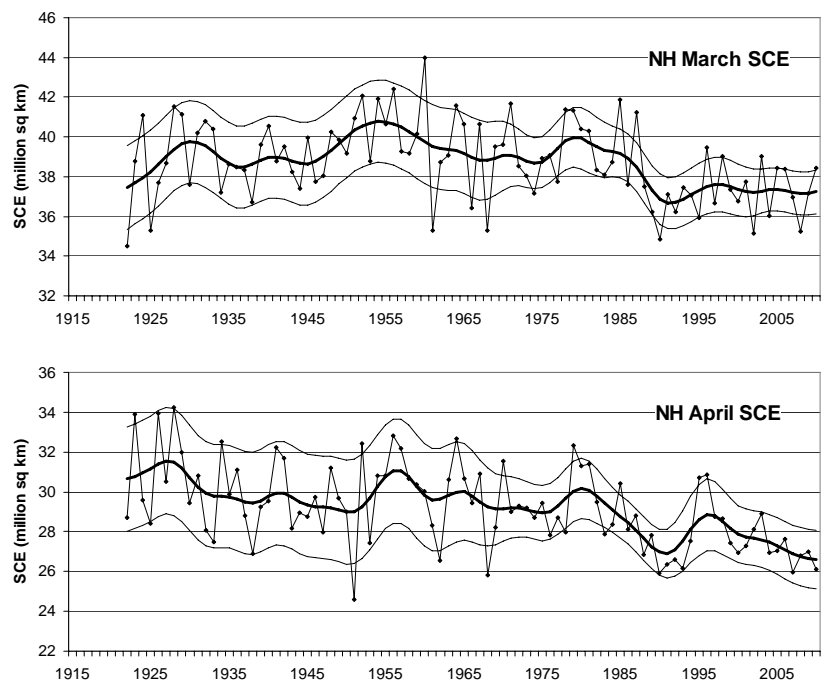

Fig. 5. Same as Fig. 4 for $\mathrm{NH}$ SCE estimated from the anomaly series using the NOAA 1979-2002 reference period mean and standard deviation (excludes Greenland which averages $2.16 \times 10^{6} \mathrm{~km}^{2}$ ).

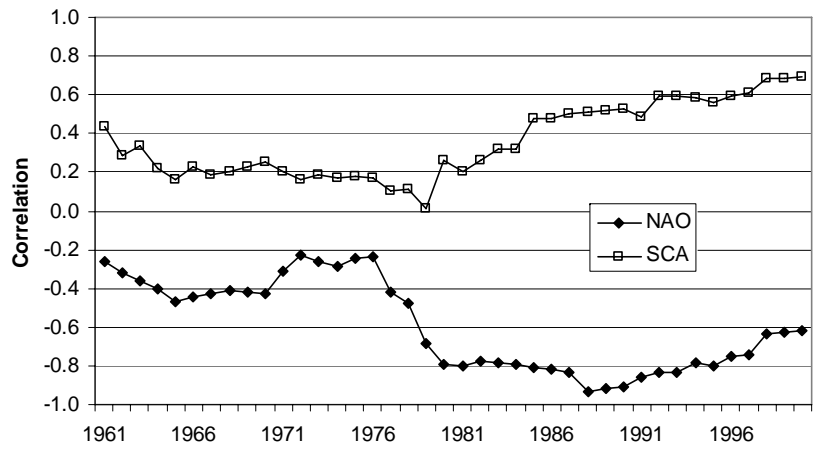

Fig. 6. Running 21-yr correlations between the NAO and SCA modes of NH winter (JFM) circulation and NH March SCE. Correlations exceeding 0.4 are nominally significant at a 0.05 level assuming data series are not autocorrelated.

Results of linear trend analysis including annual estimates of error in SCE are shown in Table 3 for the entire data period as well as for the more recent period of satellite data from 1970, along with corresponding trends in land surface air temperatures over $40-60^{\circ} \mathrm{N}$ from the CRU dataset. The 2010 updates show greater evidence of systematic decreases in continental spring SCE than those published in Brown (2000), particularly over NA where April SCE trends are now showing statistically significant decreases over the period from 1915, and an acceleration of SCE decreases over recent decades. SCE decreases over NA in March are still not statistically significant and it is plausible that the SCA and NAO patterns discussed above are playing a role, as these patterns have tended to be in modes since 1980 that contribute to cooler spring temperatures over western NA (Fig. 7).

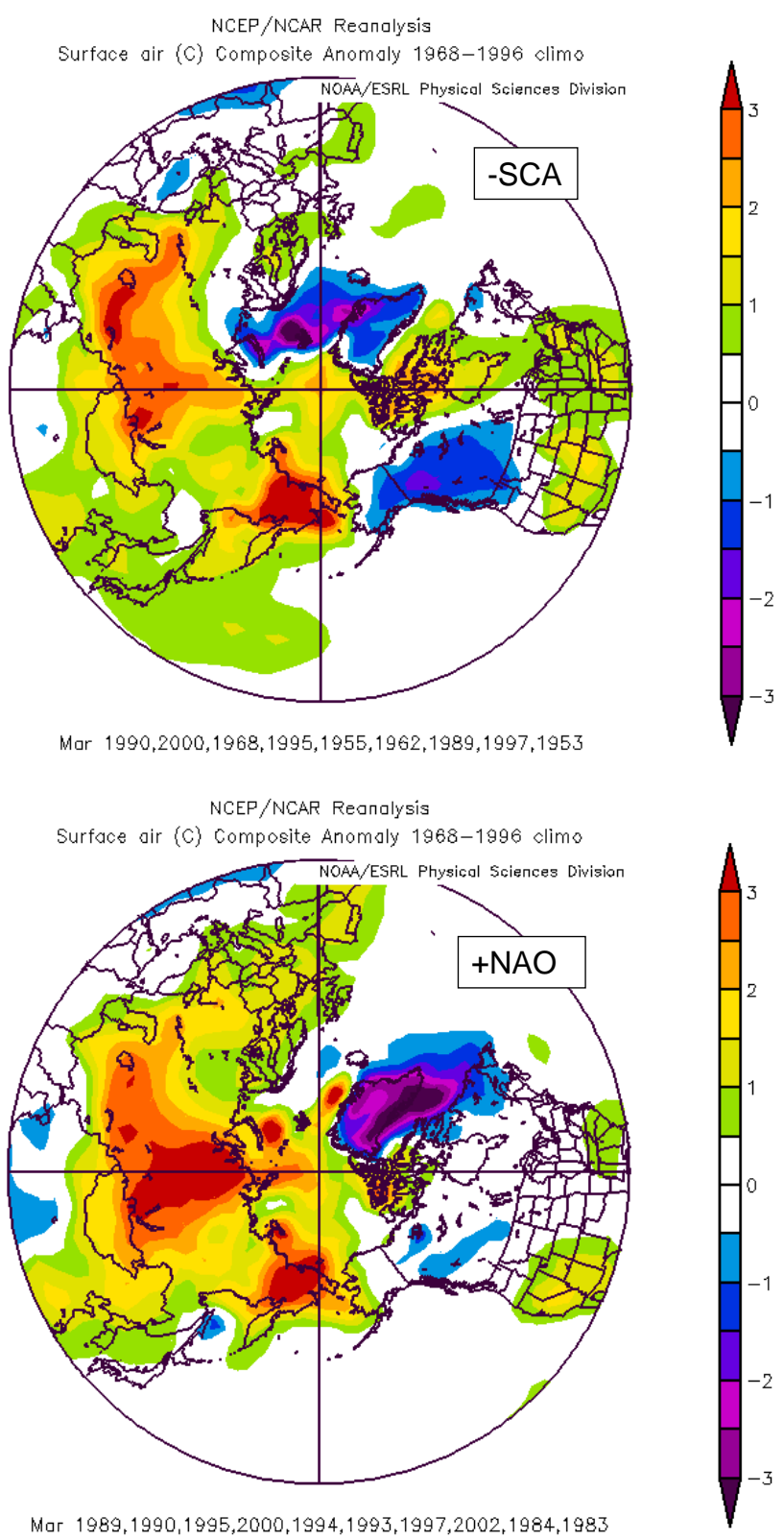

Fig. 7. Average March surface air temperature anomalies from the NCEP reanalysis for the 10 winters in the 1951-2010 period with the most negative values of the SCA index (top) and the most positive values of the NAO index (bottom). The plots were generated using the online composite plotting tool at http://www.esrl.noaa.gov/ psd/cgi-bin/data/composites/printpage.pl.

The change in NH March and April SCE is estimated to be $-3.24 \times 10^{6} \mathrm{~km}^{2}(100 \mathrm{yr})^{-1}$ and $-4.72 \times 10^{6} \mathrm{~km}^{2}$ $(100 \mathrm{yr})^{-1}$ respectively over the period from $1922-2010$ and $-7.26 \times 10^{6} \mathrm{~km}^{2}(100 \mathrm{yr})^{-1}$ and $-8.30 \times 10^{6} \mathrm{~km}^{2}$ $(100 \mathrm{yr})^{-1}$ respectively when computed over 1970-2010. One factor contributing to the higher rates of decrease over the period of satellite coverage is the fact that data start 
Table 3. Summary of linear least-squares regression trend analysis results for snow cover extent including annual error estimates. Trends significant at a 0.05 level are indicated with asterisks. The corresponding least square estimates of temperature trends are included for land areas between $40-60^{\circ} \mathrm{N}$ from the CRU dataset.

\begin{tabular}{lccccc}
\hline Region & \multicolumn{2}{c}{ March } & & \multicolumn{2}{c}{ April } \\
\cline { 2 - 3 } \cline { 5 - 6 } & $\begin{array}{c}\mathrm{SCE} \\
10^{6} \mathrm{~km}^{2}(100 \mathrm{yr})^{-1}\end{array}$ & $\begin{array}{c}\mathrm{Temp} \\
{ }^{\circ} \mathrm{C}(100 \mathrm{yr})^{-1}\end{array}$ & & $\begin{array}{c}\text { SCE } \\
10^{6} \mathrm{~km}^{2}(100 \mathrm{yr})^{-1}\end{array}$ & $\begin{array}{c}\mathrm{Temp} \\
{ }^{\circ} \mathrm{C}(100 \mathrm{yr})^{-1}\end{array}$ \\
\hline North America & & & & & \\
$1915-2010$ & -0.22 & $1.63^{*}$ & & $-0.83^{*}$ & $1.23^{*}$ \\
$1970-2010$ & -0.77 & 2.55 & & $-3.77^{*}$ & $2.84^{*}$ \\
Eurasia & & & & \\
$1922-2010$ & $-3.20^{*}$ & $3.06^{*}$ & & $-1.17^{*}$ & $2.24^{*}$ \\
$1970-2010$ & $-4.83^{*}$ & $5.98^{*}$ & & $-5.33^{*}$ & $3.57^{*}$ \\
Northern Hemisphere & & & & \\
$1922-2010$ & $-3.24^{*}$ & $2.50^{*}$ & & $-4.72^{*}$ & $1.87^{*}$ \\
$1970-2010$ & $-7.26^{*}$ & $4.69^{*}$ & & $-8.30^{*}$ & $3.30^{*}$ \\
\hline
\end{tabular}

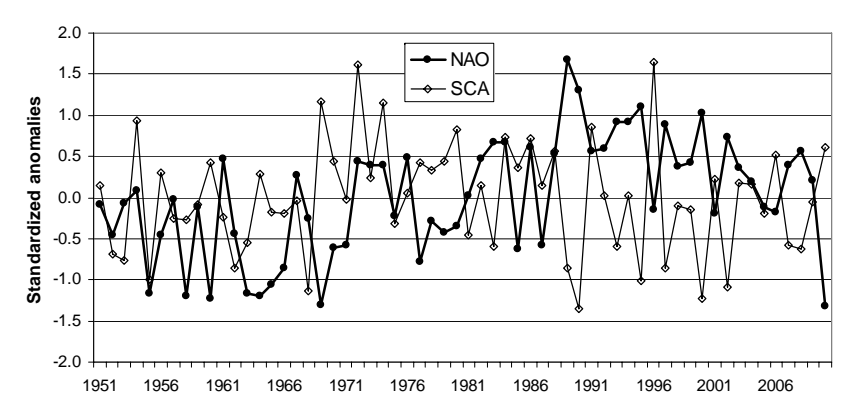

Fig. 8. Variation in standardized anomalies of winter (JanuaryMarch) values of the NAO and SCA indices over the period from 1951 to 2010 as computed by the NOAA Climate Prediction Center.

during a period when hemispheric snow cover was relatively high and include the recent period of rapid warming. The observed trends in spring SCE are consistent with the observed warming (see Table 3) and with evidence of earlier snowmelt and a shift in hydrologic regimes over $\mathrm{NH}$ land areas (e.g. Yang et al., 2002; Stewart et al., 2005; Aziz and Burn, 2006; Tan et al., 2011).

The temperature sensitivity values for the updated $\mathrm{NH}$ spring SCE series were computed using March and April monthly temperature anomaly series from the CRUTEM3 dataset averaged over $\mathrm{NH}$ land areas between 40 and $60^{\circ} \mathrm{N}$ following Brown (2000) (Table 4). A least-squares regression method was used that included the annual estimates of observational errors in SCE. The results obtained with the updated $\mathrm{NH}$ series with annual error estimates included are $-1.44 \times 10^{6} \mathrm{~km}^{2}{ }^{\circ} \mathrm{C}^{-1}\left(r^{2}=0.50\right)$ and $-2.00 \times 10^{6} \mathrm{~km}^{2}{ }^{\circ} \mathrm{C}^{-1}\left(r^{2}=0.49\right)$ for March and April respectively which are similar to the values published in Brown (2000) except that temperature explains a larger fraction of the variance with the updated series. The temperature sensitivity results shown in Table 4 suggest that EUR will dominate the NH SCE response to warming in March, while the April response will have important contributions from both continents. The larger temperature sensitivity in April is consistent with the findings of Flanner et al. (2011) that NH terrestrial snow cover feedbacks are strongest in the April-May period.

A comparison of the air temperature sensitivities computed over the pre- and post-satellite periods of data record for each continent separately (Table 4) showed that SCE temperature sensitivity in April has increased significantly over NA in the period since 1970 while it has decreased significantly over Eurasia. A number of factors could be contributing to these changes such as changing feedback potential from shifts in snowlines (e.g. see Fig. 2a in Flanner et al., 2011), changes in atmospheric circulation, and changes in spring snow depths. For example, a number of Russian studies have reported significant increases in winter snow accumulation over large areas of Eurasia (Bulygina et al., 2009; Shmakin, 2010) that contrast with trends toward generally shallower winter snow cover over Canada (Brown and Braaten, 1998; Kitaev et al., 2005). Everything being equal, shallower snowpacks will respond more quickly to temperature anomalies so the difference in recent winter snow accumulation trends between the two continents may be playing a role. Further work is required to investigate the apparent difference in snow accumulation trends between the two continents. 

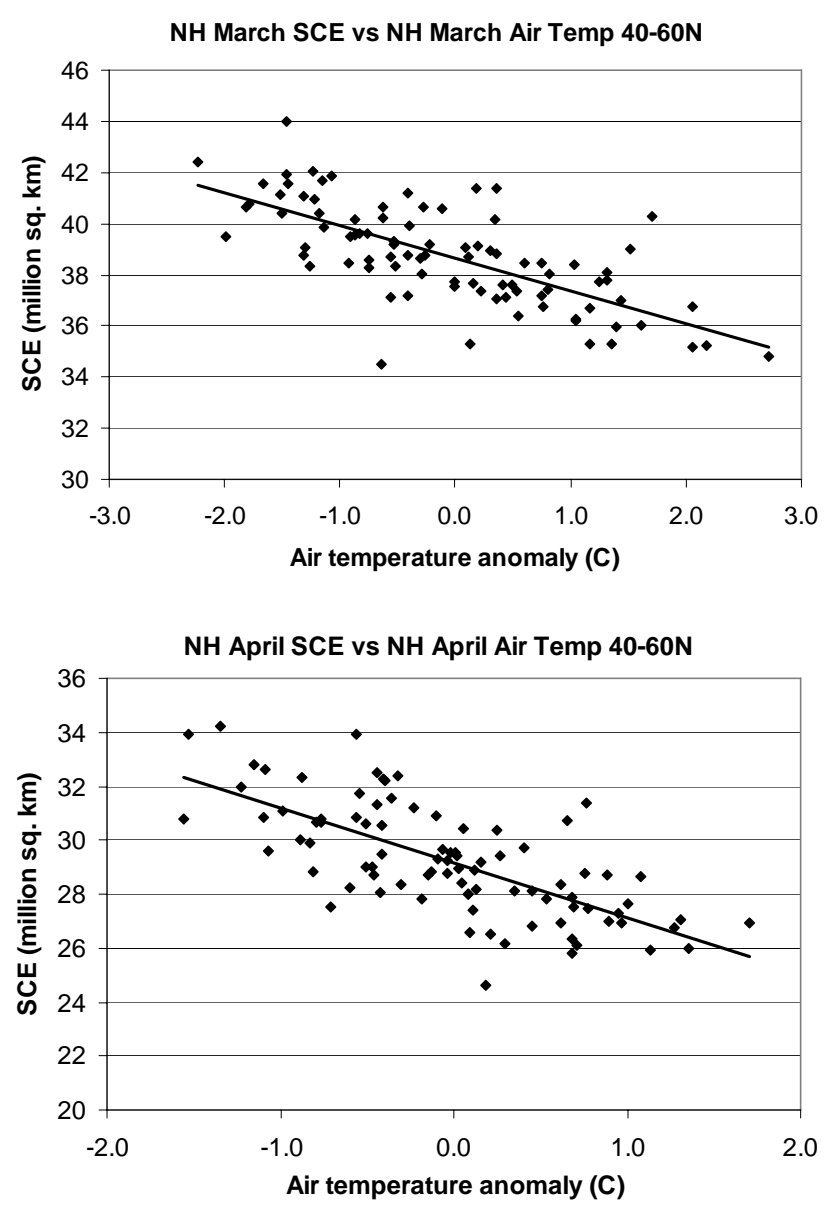

Fig. 9. Relationship between NH March and April SCE and corresponding land area air temperature anomalies over $40-60^{\circ} \mathrm{N}$ from the CRU dataset. The amount of variation explained by air temperature was $49.6 \%$ and $48.7 \%$ for March and April respectively.

\section{Summary and conclusions}

An update to the NH spring SCE series used in the 4th IPCC Assessment (Lemke et al., 2007) is provided based on the B2000 index and the latest CDR version of the NOAA weekly SCE dataset with annual error estimates obtained from regression analysis and intercomparison of multiple datasets. The analysis revealed that the $95 \%$ confidence interval in NH spring SCE is in the $\pm 5-10 \%$ range over the pre-satellite period and $\pm 3-5 \%$ over the satellite era. The multi-dataset analysis indicated there are larger uncertainties monitoring spring SCE over Eurasia than NA which is considered to be related in part to the more complex regional character of snow cover variability. The betweendataset variability was largest over northern Europe and north-central Russia in March.

Trend analysis of the updated SCE series showed that NH spring snow cover extent has undergone significant reductions over the past $\sim 90 \mathrm{yr}$ and that the rate of decrease has
Table 4. Summary of regression analysis between continental and hemispheric monthly SCE and air temperature anomalies over land areas between $40-60^{\circ} \mathrm{N}$ from the CRU dataset. Units are $10^{6} \mathrm{~km}^{2}{ }^{\circ} \mathrm{C}^{-1}$. The fraction of the variance explained by the regression is shown in parentheses. Statistically significant (0.05 level) values are indicated with a single asterisk while a plus symbol signifies that the 1970-2010 slope is significantly different (0.05 level) from the period prior to 1970 .

\begin{tabular}{lll}
\hline Region & \multicolumn{1}{c}{ March } & April \\
\hline North America & & \\
$1922-1969$ & $-0.46 *(0.38)$ & $-0.62 *(0.48)$ \\
$1970-2010$ & $-0.36 *(0.32)$ & $-0.92 *+(0.73)$ \\
$1922-2010$ & $-0.37 *(0.34)$ & $-0.81 *(0.61)$ \\
Eurasia & & \\
$1922-1969$ & $-0.94 *(0.47)$ & $-1.49 *(0.43)$ \\
$1970-2010$ & $-0.93 *(0.60)$ & $-0.94 *+(0.45)$ \\
$1922-2010$ & $-0.91 *(0.55)$ & $-1.09 *(0.49)$ \\
Northern Hemisphere & & \\
$1922-1969$ & $-1.69 *(0.51)$ & $-2.36 *(0.41)$ \\
$1970-2010$ & $-1.53 *(0.46)$ & $-1.83 *(0.40)$ \\
$1922-2010$ & $-1.44 *(0.50)$ & $-2.00 *(0.49)$ \\
\hline
\end{tabular}

accelerated over the past $40 \mathrm{yr}$. Warmer temperatures were determined to be the dominant factor in the observed SCE decreases, with air temperature anomalies over $\mathrm{NH}$ midlatitude land areas explaining $\sim 50 \%$ of the observed variability in SCE. However, there was also evidence that changes in atmospheric circulation around 1980 involving the NAO and the SCA pattern were enhancing reductions in March SCE over Eurasia. The rate of decrease in March and April NH SCE over the 1970-2010 period is $\sim 0.8$ million $\mathrm{km}^{2}$ per decade which corresponds to a $7 \%$ and $11 \%$ decrease in $\mathrm{NH}$ March and April SCE respectively from pre-1970 values. In March, most of the change is being driven by Eurasia (NA trends are not significant) but both continents exhibit significant reductions in April SCE. Evidence of recent contrasting changes in SCE temperature sensitivity over NA and EUR in April (NA increasing, EUR decreasing) may be a response to the northward shift in snowlines and/or continental differences in winter snow accumulation trends; further work is needed to more clearly understand the mechanisms involved in these differing continental snow cover responses to a changing climate.

Supplementary material (SCE time series) related to this article is available online at: http://www.the-cryosphere.net/5/219/2011/ tc-5-219-2011-supplement.zip. 
Acknowledgements. The authors thank Mary-Jo Brodzik (NSIDC) for supplying the PMW dataset and Bruce Brasnett (CMC) for the CMC global daily snow depth analysis. ECMWF is acknowledged for providing the ERA-40 data used in this study through the ECMWF data server (http://data.ecmwf.int/data/). NCEP data were provided by the Physical Sciences Division, Earth System Research Laboratory, NOAA, Boulder, Colorado (http://www.esrl.noaa.gov/psd/). Chris Derksen (Env. Canada) and Gina R. Henderson (Rutgers University) are gratefully acknowledged for helpful comments on the draft manuscript. D. Robinson acknowledges funding support from NASA MEaSURES award NNX08AP34A and NOAA Climate Program Office awards EA133E10SE2623 and NA08AR4310678. Cathy Smith of the NOAA Earth System Research Laboratory is acknowledged for her work in developing and maintaining the online analysis and plotting tools for NCEP Reanalysis output.

Edited by: S. Dery

\section{References}

Armstrong, R. L. and Brodzik, M. J.: Recent Northern Hemisphere snow extent: a comparison of data derived from visible and microwave sensors, Geophys. Res. Lett., 28, 3673-3676, 2001.

Arndt, D. S., Baringer, M. O., and Johnson, M. R.: State of the Climate in 2009, B. Am. Meteorol. Soc., 91, S1-S222, doi:10.1175/BAMS-91-7-StateoftheClimate, 2010.

Aziz, O. I. A. and Burn, D. H.: Trends and variability in the hydrological regime of the Mackenzie River Basin, J. Hydrol., 319, 282-294, doi:10.1016/j.jhydrol.2005.06.039, 2006.

Barnston, A. G. and Livezey, R. E.: Classification, seasonality and persistence of low-frequency atmospheric circulation patterns, Mon. Weather Rev., 115, 1083-1126, 1987.

Bednorz, E.: Snow cover in Eastern Europe in relation to temperature, precipitation and circulation, Intl. J. Climatol., 24, 591-601, 2004.

Brasnett, B.: A global analysis of snow depth for numerical weather prediction, J. Appl. Meteorol., 38, 726-740, 1999.

Brohan, P., Kennedy, J. J., Harris, I., Tett, S. F. B., and Jones, P. D.: Uncertainty estimates in regional and global observed temperature changes: a new dataset from 1850, J. Geophys. Res., 111, D12106, doi:10.1029/2005JD006548, 2006.

Brown, R. D. and Braaten, R. O.: Spatial and temporal variability of Canadian monthly snow depths, 1946-1995, Atmos.-Ocean, 36, 37-45, 1998.

Brown, R. D.: Northern Hemisphere snow cover variability and change, 1915-1997, J. Climate, 13, 2339-2355, 2000.

Brown, R. D., Brasnett, B., and Robinson, D.: Gridded North American monthly snow depth and snow water equivalent for GCM evaluation, Atmos.-Ocean, 41, 1-14, 2003.

Brown, R. D. and Frei, A.: Comment on "Evaluation of surface albedo and snow cover in AR4 coupled models" by Roesch, A., J. Geophys. Res., 112, D22102, doi:10.1029/2006JD008339, 2007.

Brown, R., Derksen, C., and Wang, L.: A multi-data set analysis of variability and change in Arctic spring snow cover extent, 1967-2008, J. Geophys. Res., 115, D16111, doi:10.1029/2010JD013975, 2010.
Bulygina, O. N., Razuvaev, V. N., and Korshunova, N. N.: Changes in snow cover over Northern Eurasia in the last few decades, Environ. Res. Lett., 4, 045026, doi:10.1088/1748-9326/4/4/045026, 2009.

Clark, M. P, Serreze, M. C., and Robinson, D. A.: Atmospheric controls on Eurasian snow cover extent, Intl. J. Climatol., 19, 27-40, 1999.

Fernandes, R., Zhao, H., Wang, X., Key, J., Qu, X., and Hall, A.: Controls on Northern Hemisphere snow albedo feedback quantified using satellite Earth observations, Geophys. Res. Lett., 36, L21702, doi:10.1029/2009GL040057, 2009.

Flanner, M. G., Shell, K. M., Barlage, M., Perovich, D. K., and Tschudi, M. A.: Radiative forcing and albedo feedback from the Northern Hemisphere cryosphere between 1979 and 2008, Nat. Geosci., 4, 151-155, doi:10.1038/ngeo1062, 2011.

Foster, J., Liston, G., Koster, R., Essery, R., Behr, H., Dumenil, L., Verseghy, D., Thompson, S., Pollard, D., and Cohen, J.: Snow cover and snow mass intercomparisons of general circulation models and remotely sensed datasets, J. Climate, 9, 409-426, 1996.

Frei, A. and Robinson, D. A.: Northern Hemisphere snow extent: regional variability 1972-1994, Intl. J. Climatol., 19, 1535-1560, 1999.

Frei, A., Hughes M. G., and Robinson, D. A.: North American snow extent: 1910-1994, Intl. J. Climatol., 19, 1517-1534, 1999.

Frei, A., Brown, R., Miller, J. A., and Robinson, D. A.: Snow mass over North America: observations and results from the second phase of the Atmospheric Model Intercomparison Project (AMIP-2), J. Hydrometeorol., 6, 681-695, 2005.

Gutzler, D. S. and Rosen, R. D.: Interannual variability of wintertime snow cover across the Northern Hemisphere, J. Climate, 5, 441-1447, 1992.

Hall, A. and Qu, X.: Using the current seasonal cycle to constrain snow albedo feedback in future climate change, Geophys. Res. Lett., 33, L03502, doi:10.1029/2005GL025127, 2006.

Helfrich, S. R., McNamara, D., Ramsay, B. H., Baldwin, T., and Kasheta, T.: Enhancements to, and forthcoming developments in the Interactive Multisensor Snow and Ice Mapping System (IMS), Hydrol. Proc., 21, 1576-1586, 2007.

Henderson, G. and Leathers, D.: European snow cover extent variability and associations with atmospheric forcings, Intl. J. Climatol., 30, 1440-1451. doi:10.1002/joc.1990, 2010.

Kalnay, E., Kanamitsu, M., Kistler, R., Collins, W., Deaven, D., Gandin, L., Iredell, M., Saha, S., White, G., Woollen, J., Zhu, Y., Chelliah, M., Ebisuzaki, W., Higgins, W., Janowiak, J., Mo, K. C., Ropelewski, C., Wang, J., Leetmaa, A., Reynolds, R., Jenne, R., and Joseph, D.: The NCEP/NCAR Reanalysis Project, Bull. Am. Met. Soc., 77, 437-471, 1996.

Kitaev, L., Førland, E., Razuvaev, V., Tveito, O. E., and Krueger, O.: Distribution of snow cover over Northern Eurasia, Nord. Hydrol., 36, 311-319, 2005.

Lemke, P., Ren, J., Alley, R. B., Allison, I., Carrasco, J., Flato, G., Fujii, Y., Kaser, G., Mote, P., Thomas R. H., and Zhang, T.: Observations: Changes in Snow, Ice and Frozen Ground, in: Climate Change 2007: The Physical Science Basis. Contribution of Working Group I to the Fourth Assessment Report of the Intergovernmental Panel on Climate Change, edited by: Solomon, S., Qin, D., Manning, M., Chen, Z., Marquis, M., Averyt, K. B., Tignor, M., and Miller, H. L., Cambridge University Press, Cam- 
bridge, United Kingdom and New York, NY, USA, 2007.

McCabe, G. J. and Wolock, D. M.: Long-term variability in Northern Hemisphere snow cover and association with warmer winters, Climatic Change, 99, 141-153, 2010.

Overland, J. E., Adams, J. M., and Bond, N. A.: Decadal variability of the Aleutian Low and its relation to high-latitude circulation, J. Climate, 12, 1542-1548, 1999.

Ramsay, B.: The interactive multisensor snow and ice mapping system, Hydrol. Proc., 12, 1537-1546, 1998.

Robinson, D. A., Dewey, K. F., and Heim, R. R.: Global snow cover monitoring: an update, Bull. Am. Met. Soc., 74, 16891696, 1993.

Roesch, A.: Evaluation of surface albedo and snow cover in AR4 coupled climate models, J. Geophys. Res., 111, D15111, doi:10.1029/2005JD006473, 2006.

Savoie, M. H., Armstrong, R. L., Brodzik, M. J., and Wang, J. R.: Atmospheric corrections for improved passive microwave snow cover retrievals over the Tibet Plateau, Rem. Sens. Environ., 113, 2661-2669, 2009.

Shmakin A. B.: Climatic characteristics of snow cover over North Eurasia and their change during the last decades, Ice and Snow, 1, 43-57, 2010 (in Russian with English summary).

Stewart, I. T., Cayan, D. R., and Dettinger, M. D.: Changes toward earlier streamflow timing across western North America, J. Climate, 18, 1136-1155, 2005.

Tan, A., Adam, J. C., and Lettenmaier, D. P.: Change in spring snowmelt timing in Eurasian Arctic Rivers, J. Geophys. Res., 116, D03101, doi:10.1029/2010JD014337, 2011.
Trenberth, K. E., Jones, P. D., Ambenje, P., Bojariu, R., Easterling, D., Tank, A. K., Parker, D., Rahimzadeh, F., Renwick, J. A., Rusticucci, M., Soden, B., and Zhai, P.: Observations: Surface and Atmospheric Climate Change, in: Climate Change 2007: The Physical Science Basis. Contribution of Working Group I to the Fourth Assessment Report of the Intergovernmental Panel on Climate Change, edited by: Solomon S, Qin, D., Manning, M., Chen, Z., Marquis, M., Averyt, K. B., Tignor, M., and Miller, H. L., Cambridge University Press, Cambridge, United Kingdom and New York, NY, USA, 2007.

Uppala, S. M., Kållberg, P. W., Simmons, A. J., Andrae, U., da Costa Bechtold, V., Fiorino, M., Gibson, J. K., Haseler, J., Hernandez, A., Kelly, G. A., Li, X., Onogi, K., Saarinen, S., Sokka, N., Allan, R. P., Andersson, E., Arpe, K., Balmaseda, M. A., Beljaars, A. C. M., van de Berg, L., Bidlot, J., Bormann, N., Caires, S., Chevallier, F., Dethof, A., Dragosavac, M., Fisher, M., Fuentes, M., Hagemann, S., Hólm, E., Hoskins, B. J., Isaksen, L., Janssen, P. A. E. M., Jenne, R., McNally, A. P., Mahfouf, J.-F., Morcrette, J.-J., Rayner, N. A., Saunders, R. W., Simon, P., Sterl, A., Trenberth, K. E., Untch, A., Vasiljevic, D., Viterbo, P., and Woollen, J.: The ERA-40 re-analysis, Quart. J. R. Meteorol. Soc., 131, 2961-3012, doi:10.1256/qj.04.176, 2005.

Watanabe, M. and Nitta, T.: Decadal changes in the atmospheric circulation and associated surface climate variations in the northern hemisphere winter, J. Climate, 12, 494-510, 1999.

Yang, D., Kane, D. L., Hinzman, L. D., Zhang, X., Zhang, T., Ye, H., and Yang, D.: Siberian Lena River hydrologic regime and recent change, J. Geophys. Res., 107, 4694, doi:10.1029/2002JD002542, 2002. 